\title{
Expression of Collagenlike Sequences by a Tumor Virus, Herpesvirus Saimiri
}

\author{
PETER GECK, ${ }^{1}{ }^{\dagger *}$ SCOTT A. WHITAKER ${ }^{1}{ }^{\dagger}$ MARIA M. MEDVECZKY ${ }^{1}{ }^{\dagger}$ AND PETER G. MEDVECZKY ${ }^{1,2} \dagger$ \\ Departments of Pharmacology ${ }^{1}$ and Molecular Genetics and Microbiology, ${ }^{2}$ University of Massachusetts Medical School, \\ Worcester, Massachusetts 01655
}

Received 20 December 1989/Accepted 2 April 1990

\begin{abstract}
Sequencing demonstrates that the oncogenic regions of a group A strain and a group $\mathbf{C}$ strain of herpesvirus saimiri are nonhomologous. A bicistronic viral mRNA from this region is transcribed in tumor cells transformed by a highly oncogenic group $\mathrm{C}$ virus. The first open reading frame is homologous to collagen; no such sequences were found in group $A$ or $B$ strains. This is the first report that a virus encodes for sequences similar to those of a connective tissue protein.
\end{abstract}

Unlike alphaherpesvirus (e.g., herpes simplex virus) and betaherpesvirus (e.g., cytomegaloviruses), members of the gammaherpesvirus subfamily (Epstein-Barr virus, herpesvirus saimiri, herpesvirus ateles, and herpesvirus sylvilagus) are able to induce lymphoproliferative diseases $(39,40)$. Herpesvirus saimiri is used as a model for studying human lymphoproliferative malignancies, since its genetic structure and molecular biology are related to those of the human Epstein-Barr virus (14). Herpesvirus saimiri shows high oncogenicity in New World monkeys (13) and New Zealand White rabbits $(9,30)$, The transformed cells of the acute lymphomas and leukemias induced by the virus are CD8positive T lymphocytes with NK activity $(21,24)$ and carry a circular form of the originally linear virion DNA with 110 kilobase pairs $(\mathrm{kbp})$ of unique sequences (L-DNA, $36 \%$ $\mathrm{G}+\mathrm{C}$ ) flanked by tandem repeats (H-DNA, $71 \% \mathrm{G}+\mathrm{C})(3)$.

The rightmost L-DNA region (polarity analogous to that of Epstein-Barr virus DNA) is thought to contain the oncogene(s). This hypothesis is based on four lines of evidence: (i) the region is always retained in immortalized cell lines (23, 44), (ii) deletions in this region result in loss of oncogenicity without any effect on virus replication $(11,25)$, (iii) variability of this sequence forms three homology groups (A, B, and C) with different oncogenic potencies $(30,32)$, and (iv) in intergroup recombinants the characteristic oncogenic trait is conveyed by this region (30). In strain 11 of group $A$, unique features established so far in this region involve five genes for U-type small RNAs $(27,51)$, a dihydrofolate reductase gene $(50)$, and an open reading frame with no homology to known sequences but with a presumed function in immortalization (35), as shown by deletion mapping. Only the U-type small RNAs are transcribed, and no corresponding mRNAs have been detected in strain 11-transformed cells.

Efforts in this laboratory were focused on the rightmost L-DNA region of group C strain 484-77, which is highly oncogenic in rabbits. Several lymphoblastoid tumor-derived cell lines have been established from thymuses and spleens

\footnotetext{
* Corresponding author.

$\dagger$ Present address: Department of Medical Microbiology and Immunology, College of Medicine, University of South Florida, Box 10, Tampa, FL 33612-4799.
}

of tumor-bearing animals (30) and cultured in RPMI medium supplemented with $20 \%$ fetal calf serum and $10 \mu \mathrm{g}$ of gentamycin sulfate per $\mathrm{ml}$. The cell line used in these experiments (484-77T) had been continuously cultured for approximately 1 year prior to RNA isolation and was shown to carry no linear viral genomes but approximately 50 copies of circular viral genomes per cell. No virus production was detected by cocultivation on owl monkey kidney cells, so lytic-cycle genes are probably not expressed.

Cloning the 6.4-kbp 484-77 right-hand terminal L-DNA. The $6.4-\mathrm{kbp}$ clone (containing $6.2 \mathrm{kbp}$ of L-DNA) was generated by Pst $\mathrm{I}$ digestion of a clone consisting of the rightmost terminal 14-kbp L-DNA in a 21-kbp insert of 484-77 cloned into the vector $\mathrm{pHyg}$, which confers resistance to hygromycin B $(30,47)$. The original $21-\mathrm{kbp} 484-77$ clone was generated by Sau3AI partial digestion of the full-length 484-77 viral genome followed by sucrose gradient size fractionation and cloning into the $\mathrm{pHyg}$ vector (14). The 6.4-kbp fragment was subcloned into the PstI site of the Bluescript M13-SK vector (Stratagene). A set of small subclones was then created by taking advantage of the mapped restriction endonuclease sites, and a library of clones with "nested deletions" was also generated by standard protocols $(18,19)$ (Fig. 1).

A virus-specific mRNA transcribed in tumor cell lines is mapped in a region of the genome involved in oncogenicity. Cytoplasmic RNA was isolated by Nonidet P-40 lysis, as described previously (12), from the cell line (484T) derived from strain 484-77-induced tumor, from the strain 11-transformed cell line (1670), and from uninfected lymphocytes. The preparations were poly(A) selected and probed on Northern (RNA) blots by using standard protocols $(31,38$, 49) with the 6.4-kbp sequence containing the 6.2-kbp rightmost L-DNA region. The probe did not hybridize to strain 11-specific or uninfected cytoplasmic RNAs, but in the cells derived from 484-77-induced tumor, a 1.2-kilobase (kb) RNA with poly(A) tail was detected (Fig. 2) (four small RNAs in total unselected RNA preparations were also detected; data not shown).

Mapping and analysis of the mRNA was carried out by RNase protection assays and primer extension. Nearly 50 overlapping subclones were used for strand-specific RNA 


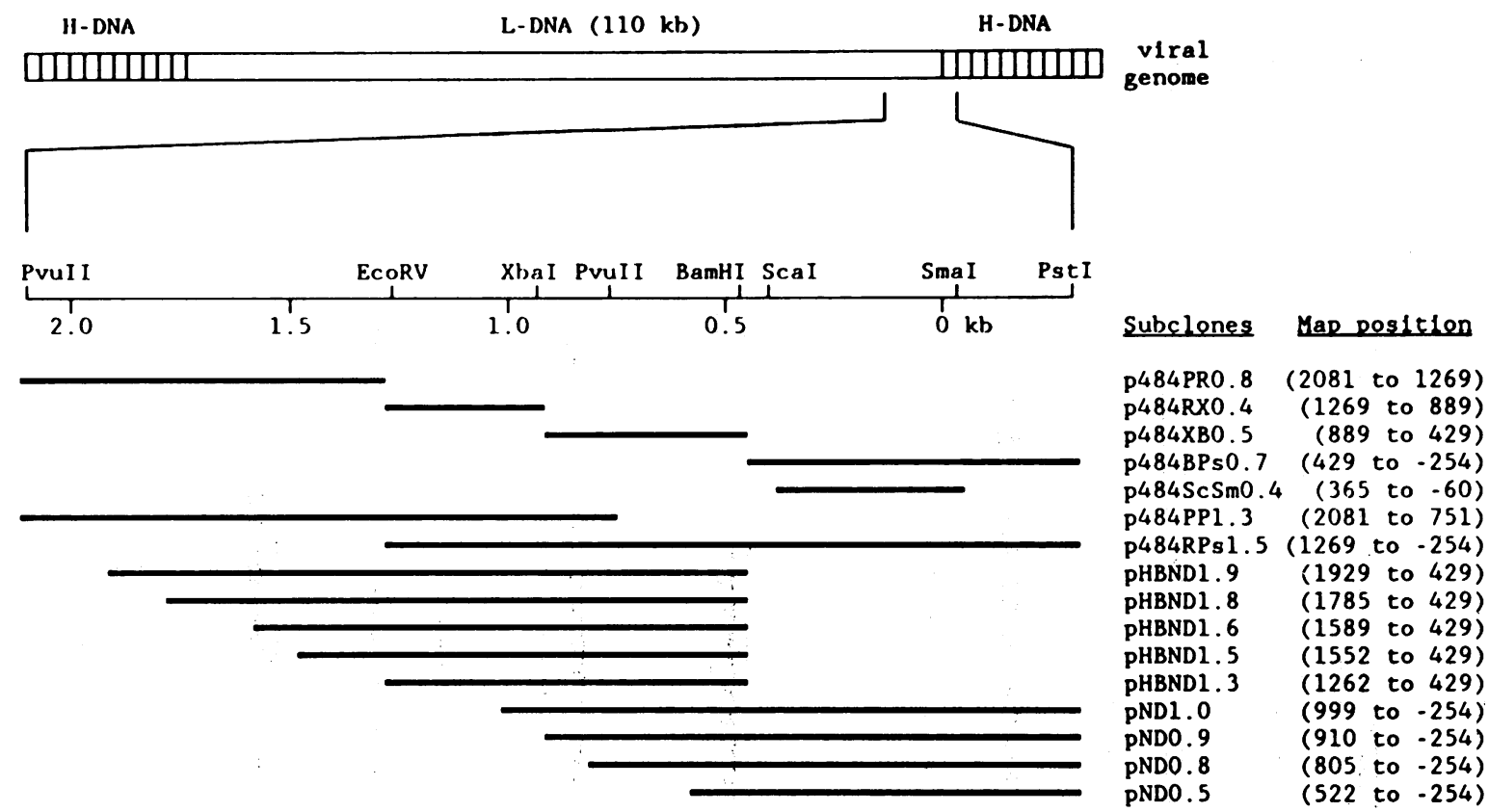

FIG. 1. Map of subclones of the rightmost 2-kbp L-DNA region. Exact positions (Map position) of the subclones and restriction endonuclease sites used for subcloning are indicated. Two sets of clones created by nested deletions are shown. One set (pND1.0 to pND0.5) was obtained by unidirectional deletions only, and the other (pHBND1.9 to pHBND1.3) had the BamHI-PstI fragment deleted also.

probe synthesis by established protocols (33). The highly labeled, single-stranded RNA probes were hybridized in solution to the RNA preparations from $484 \mathrm{~T}$ cells. RNase treatment by the method of Zinn et al. (55) reduced the sizes of the probes, and only those fragments of the probes which became protected by the mRNA remained intact. The total region of protection finally identified the mRNA-coding

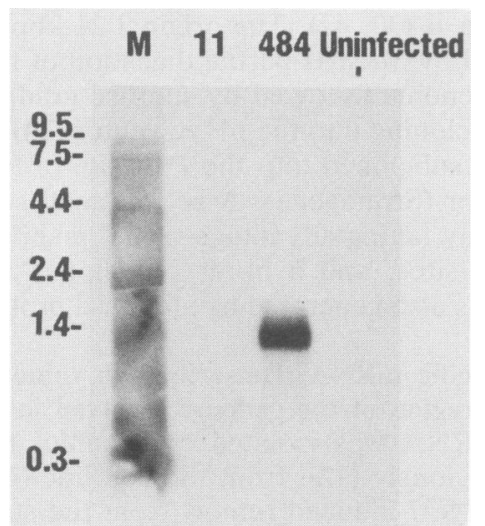

FIG. 2. Northern blot hybridization of poly(A) ${ }^{+}$RNAs from uninfected and tumor-derived cell lines. RNA $(4 \mu \mathrm{g})$ was applied in each lane for formaldehyde-1\% agarose gel electrophoresis. Numbers at left indicate sizes in kilobase pairs. Lane M, RNA size marker (six [ $\left.{ }^{32} \mathrm{P}\right] \mathrm{pCp}$-labeled synthetic poly(A)-tailed RNAs [Bethesda Research Laboratories, Gaithersburg, Md.]); lane 11, cytoplasmic poly(A)-selected RNA of a group A strain (strain 11)transformed monkey cell line (1670); lane 484, cytoplasmic, poly(A)selected RNA of a group C strain (strain 484-77)-transformed, thymus-derived, rabbit tumor cell line (484T); lane Uninfected, cytoplasmic, poly(A)-selected RNA of an uninfected human lymphoblastoid cell line (Jurkat). The nick-translated DNA probe represented cloned rightmost L-DNA sequences between nucleotides 1 and 6200 , with a portion of the adjoining H-DNA $(-1$ to -254$)$.
DNA sequences. The results of such RNase protection assays with some of the subclones are shown in Fig. 3. The data show that the transcribed region is an intronless sequence between nucleotide positions 1336 and 140 (position +1 is the first nucleotide leftward from the last intact repetitive unit of the right-hand H-DNA; see Fig. 5). Rightward transcription was indicated by the strandedness of protection assays.

The exact $5^{\prime}$ end was determined by primer extension analysis by standard protocols $(22,29)$. An oligonucleotide primer complementary to a sequence close to the $5^{\prime}$ end of the mRNA (as estimated by preliminary data) between map positions 1248 and 1268 (5' CCTGTTTCTTCAGTTGGATAT $\left.3^{\prime}\right)$ was synthesized, labeled with $\left[\gamma^{-32} \mathrm{P}\right] \mathrm{ATP}$ by T4 polynucleotide kinase, hybridized at $22^{\circ} \mathrm{C}$ to $4 \mu \mathrm{g}$ of oligo(dT)selected RNA, and extended by reverse transcriptase toward the $5^{\prime}$ end of the mRNA to serve as template. Electrophoresis of the extended primer with a sequencing marker identified the number of incorporated nucleotides (Fig. 4). The data demonstrate that the primer was extended with 68 nucleotides from the 3 '-terminal nucleotide of the primer at map position 1268 . In addition to the major band at 68 nucleotides, minor bands at 67 and 66 nucleotides refer to the irregular $5^{\prime}$ end of the mRNA (5' cap structure), where the reverse transcriptase occasionally preterminates.

Nucleotide sequence and predicted amino acid sequence of ORF1 of the 1.2-kb mRNA are homologous to collagen. The gene and flanking regions of the 1.2-kbp mRNA were sequenced by the dideoxynucleotide-chain termination method by standard protocols $(43,48)$ and analyzed with the DNASTAR computer program (DNASTAR, Inc., Madison , Wis.) (Fig. 5). The established map positions of the mRNA were confirmed by the consensus sequences for transcription regulation. A typical TATA box was found 28 nucleotides upstream of the first nucleotide of the mRNA, at position 1335; a primary-transcript terminal cleavage signal 


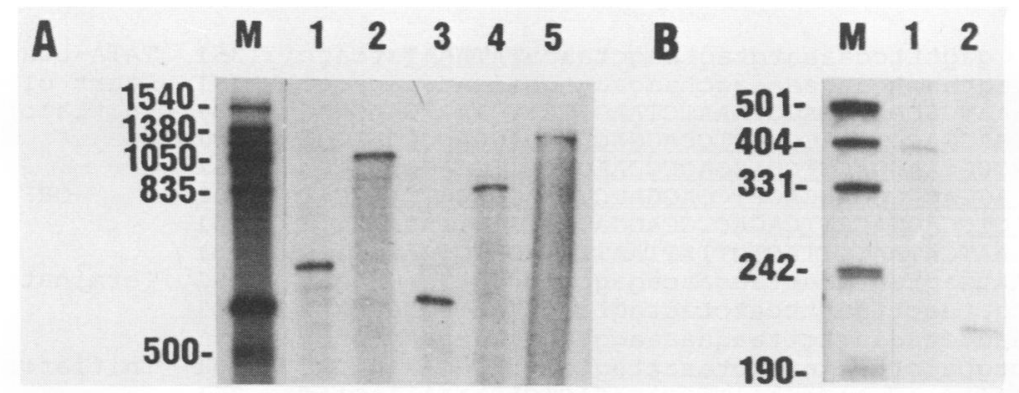

C

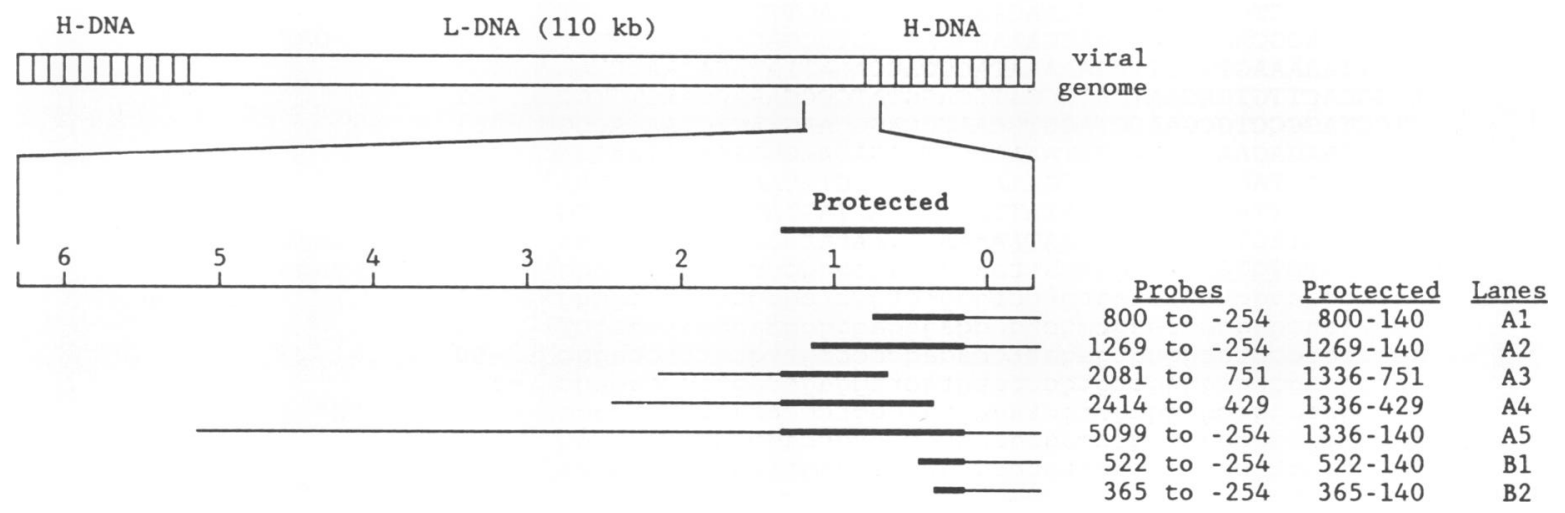

FIG. 3. Mapping of mRNA by RNase protection assay. (A) Autoradiogram from a denaturing $3 \%$ polyacrylamide gel electrophoresis displaying the larger protected fragments. Numbers at left indicate lengths in nucleotides. Lane M, RNA size marker synthesized by T7 RNA polymerase on templates of determined size; lanes 1 through 5, protected RNA fragments (map positions of probes and protected fragments are depicted in panel C). (B) Autoradiogram from a denaturing $6 \%$ polyacrylamide gel electrophoresis displaying the smaller protected fragments. Lane M, DNA size marker (pUC19 HpaII digestion, labeled with [ $\left.{ }^{32} \mathrm{P}\right] \mathrm{dCTP}$ by using the Klenow fragment of Escherichia coli DNA polymerase); lanes 1 and 2, protected RNA fragments (map positions of probes and protected fragments are depicted in panel C). (C) Map of probes and protected fragments. Numbers on the map indicate kilobase pairs. The exact map positions of probes ( $\rightarrow$ ) and protected fragments (-) are also shown, with references to the corresponding lanes in panels A and B.

TGTGTGTG sequence was localized at the $3^{\prime}$ end of the mRNA; and a poly(A) addition signal AATAAA sequence was identified 40 nucleotides upstream. Two major open reading frames (ORF1 and ORF2) were revealed. ORF1 codes for 99 amino acids between nucleotides 1290 and 994 (Fig. 2). The coding capacity of ORF2 is 214 amino acids from nucleotides 812 to 171 . The latter is not discussed further, since no significant homology was found in the GenBank data.

In the sequence of ORF1, however, a remarkable structure has been revealed. Of the total 297 nucleotides, 162 code for a repetitive sequence with an element of 18 nucleotides repeated in tandem nine times, with minor irregularities in the first and last units (Fig. 5A). High similarity was found between ORF1 and different forms of collagen of diverse origin (not shown). The greatest similarity to ORF1 was displayed by a collagen sequence of a nematode, Caenorhabditis elegans (26), for which 116 of 162 nucleotides in the repetitive region were identical $(71.6 \%)$; the flanking nonrepetitive sequences of ORF1 also showed similarity to collagen (Fig. 5B). High homology was demonstrated when amino acid sequences of various known collagens and the putative herpesvirus saimiri protein sequence were compared (Fig. 6).

Collagenlike sequences are present in group $\mathrm{C}$ strains of herpesvirus saimiri and absent in group $A$ and $B$ strains. To obtain virion DNA for Southern hybridization, OMK cells

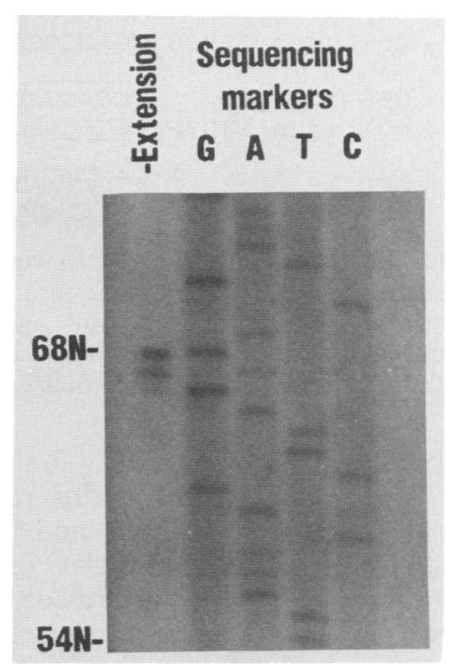

FIG. 4. Primer extension analysis of the $5^{\prime}$ end of the mRNA. Autoradiogram from a denaturing $6 \%$ polyacrylamide gel electrophoresis showing the extended primer together with a size marker sequencing ladder. Only a portion of the sequencing gel is shown. The sequence itself is unrelated and is used merely as a marker. Lane Extension, Extended primer; lanes G, A, T, and C, part of a size marker sequencing ladder, shown only from nucleotide (N) 54 . $\mathrm{G}, \mathrm{A}, \mathrm{T}$, and $\mathrm{C}$ label the individual chain termination reactions. 
A

gagtttccaaatgtagtaagctaacaTATAAATatcagc agaaaatagagtaacAcaagaaacagctaacaagagcaacacaaacacgc ttgaaagaaaATGGCAAGCGAGCCAAACCTAAGATATCCAACTGAAGAAA CAGGAGATCGAGGACCTCAAGGACCT CCAGGACCTCCAGGACCCCAAGGA CCTCCAGGACCCCAAGGACCTCCAGGACCCCAAGGACCTCCAGGACCCCA AGGACCTCCAGGACCCCAAGGACCTCCAGGACCCCAAGGACCTCCAGGAC CCCAAGGACCTCCAGGACCTTCAGACTCCAGGATTGTTTGTAACAAACTT ATTGCTTGGAATCATAATTTTACTCTTATTAATTATAGTTGCGATCTTAC TGGTGTCTAAttagtagtaaactaagaacagagcaagcagtatagaagag agtaattatgctagcttaatttcatctagtagtcagttgtgtagaacttt ttattagtaaatctagaagtgttaagaaaaaggtagagaaagtagtgacc tttattagctgcatcttcatatctctaaattagtaagtATGGAAAACCAG AGAGAAGAAATAGAACTAACAGAAATTCCAGAGACTGAGAAAAAAAGAAC AGCTGAAGAAAAATTATTATCATGCTCTGCTGAAACTGCTGAAGAAAAGG TATCATTATGCTCTGAAGAAACTACAGACACGTCAAGCAGTTCTAGCAGT GAGCAAACACCTGCTCCTATAGAAGTAAACGTTAACATTCAAACGAGCAC ATACTTGCCTCAGAACGCGGCAACAAACTTGAACAGTTTGTACACAAGTT TTGAAGACGCAAGGGCACAAGGAAAAGGACTGGTGCGACACAATTCGGAC GATTTAAAAAGTTTTTTAGAAAAATACCCACCAGATTATAGAAAACCTAA ACGGGACTTGTCAGAATCATGGGATCCAGGTATGCCGAAACCAACTTTGC CTCCTAGGCCTGCGAACCTAGGTGCAAGCCAGGCAAGTACTGTAAGACGG CATGTAAGAGAACAAAATTTTAAACAGCTTAGAGAACGTAAAGCTAATGA AGGGAAAATAGTAAAAGAITTGAAAAGACTTGAGTACAAAGTTAATATAA TTCTTTGTTTAGTAGTTGTTATATTAGCTATAATATTATTACTAACTGGG CTAAGTATACTGTTCATAAGAATAAAAAGTTAAtt taacaaagaatt taa caaataTGTGTGTGcatggtcattaaaagaagcgggccccaagcagtggg cgctgggcagctggaaaaatgtcctgggcgtggctagagcgagctcgggg ggcaaagcgagcagcgagcggctgcggagggagggggaagggattgagcT gecccgccctctggggtgagattccagagcccetgttgtgtccccaggc caccgcaggcceggggetgtgcccetgtgcttggagccagtccccagagc cctggctaggccgaggcgctgctagagtaagggtcccacaactgttcagg ccccccagggggagagcccagcgcagcgctctgccgggtaggggggggg tagctggctcccecccacctctgcgtgaagcagagtgcatgcagccect

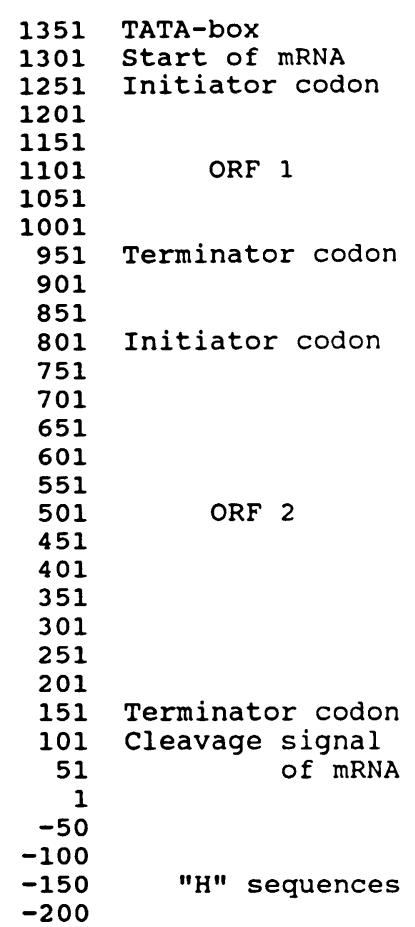

ORF 1 ATGGCAAGCGAGCCA AACTAAG TATOCA CI GA AGA CAGGAGATCG collagen 1109 GCTATTTICGAGCCACTdACCCDAGAGCAdDAGEAGAGCAGGAGACTC

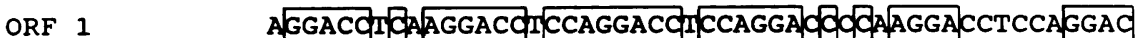
collagen 1159 dGGACOAddAGGACOACCAGGACOACCAGGAGCADCAGGAAACGACGGAC

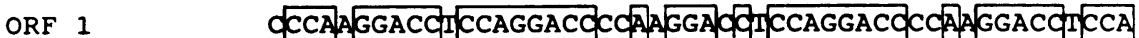
collagen 1209 GCCAdGGACOACCAGGACOAA GGAOdCCAGGACOAGAOGGACOACCA

ORF 1 GGAOCOCA GGACCTOCA GGACCOCA AGGACOICCAGGACOCOCA GGACD

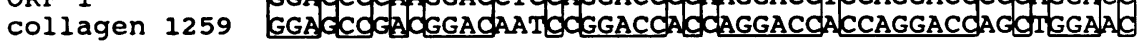

ORF 1 TCCAGGACCTTCAGACTOAAGGATTGTTGTAACAAACTTATIECTIGGA collagen 1309 OCCAGGAGAGAAGGAAT CIGTCCAATTTGTITAAAAAGGIIAGGAIAAT

ORF 1 ATCARA TTITACPCTTATTAAPTARAGTTGCGATCTPACTGGIGTCTAA collagen 1359 TATA AIITIGIAAIAITTCAGGIATIIIGCGCTCTCGAIIGGAGGAGTCITC

FIG. 5. Nucleotide sequence of the mRNA coding region. (A) Nucleotide sequence between nucleotides -250 and 1390 . Transcription consensus sequences and open reading frames are shown in capital letters. A (at nucleotide 1335), Start point of transcription; $\mathrm{T}$ (at nucleotide 1), first nucleotide of L-DNA. The initiation and termination codons are printed in boldface letters. In ORF1, each repetitive unit is underlined. Negative numbers refer to a portion of the first intact $\mathrm{H}$ unit. (B) Comparison of ORF1 and a collagen sequence $(C$. elegans; GenBank identifier, CELCOL1G). In the collagen sequence, an insert of AGTGAGT at nucleotide 1335 is omitted. Boxes represent full homology.

were infected with the following strains representing the three subgroups: strains 484-77, 487-77, and 505-77 (all group C); strain 11 (group A); and strain S295C (group B). DNA was isolated from the virions as described previously (30). Restriction endonuclease digestions, electrophoresis, vacuum blotting, and hybridization with nick-translated DNA probe were performed by using standard protocols $(31,38$, 49). The ORF1 sequence was present in the three group $C$ strains tested, with no variability in length of the ORF1containing fragments (Fig. 7).

As expected, no hybridization was detected in a representative from group A or B. No homology was found between ORF1 or ORF2 nucleic acid or predicted protein sequence and the published right-end sequence of strain 11 (group A) (35) with AALIGN or ALIGN programs (DNASTAR, Inc.) or FASTA programs ALIGN, RDf2, or PLFASTA (37) (data not shown).

Sequencing the oncogenic DNA region of a highly oncogenic herpesvirus saimiri strain and studying its expression by transcription analysis resulted in three major and potentially important observations. (i) Earlier hybridization data that the rightmost L-DNA sequences are nonhomologous among different groups of herpesvirus saimiri have been confirmed by sequencing. (ii) This is the first report in which an mRNA from the oncogenic region in transformed cells has been detected and characterized. (iii) This is also the first 
HVS TGDRGPQGPPGP PGPQGPPGPQ - - -GPPGPQGPPGPQGPPGPQGPPGPQGPPGPPGPPGPSDSRIVCNKLIAWN

\begin{tabular}{|c|c|c|c|c|c|c|c|c|c|c|c|c|c|c|c|}
\hline 1 & $\mathbf{P} \mathbf{S}$ & $\mathbf{P}$ & & AP & ND & P-- - & & K A & D & & $A D$ & GS & $\mathbf{P}$ & A $T$ & EKGICPK \\
\hline & $\mathbf{P}$ & EA & $\mathbf{A}$ & FA & & $A D \cdots$ & Q & AK E & E DT & $\mathrm{VK}$ & DA & & $\mathbf{A}$ & $\mathbf{A}$ & KGP GAAGPPG TG \\
\hline & S AS & A & $\mathbf{R}$ & SA & $\mathbf{S}$ & KDGLN & L & I & $\mathbf{R}$ & RT & DA & $\mathbf{A}$ & $\mathbf{P}$ & & PSGGYDLSF PQPP \\
\hline & S AS & $\mathbf{A}$ & $\mathbf{R}$ & SA & A & KDGLN & L & I & $\mathbf{R}$ & RT & DA & V & $\mathbf{P}$ & & PSAGFDFSF PQPP \\
\hline & $S$ AS & A & $\mathbf{R}$ & SA & $\mathbf{S}$ & KDGLD & L & I & $\mathbf{R}$ & RT & DA & $\mathbf{S}$ & $\mathbf{P}$ & & PSGGYDLSFFPEPP \\
\hline & S PA & $\mathbf{R}$ & SA & $\mathbf{A A}$ & KD & LNGLP & I & $\mathbf{P}$ & R RT & EV & V & & $\mathbf{P}$ & & S GFDLDGGGRYY \\
\hline
\end{tabular}

FIG. 6. Comparison of amino acid homology in the repetitive region with alpha(1) chain sequences of type I collagens from different species. Amino acids differences are shown relative to the herpesvirus saimiri sequence between amino acid positions 14 and 84 . Empty spaces represent identical amino acids. Lines 1, 2, 3, 4, 5, and 6 are the nematode (CELCOL1G), murine (A23982), bovine (CGB01S), human (CGHU1S), rat (CGRT1S), and avian (CGCH1S) corresponding sequences, respectively (GenBank identifiers are in parentheses). Similar degrees of homology were found between the saimiri collagenlike sequence and other collagen types (not shown). $X$, Insert in the murine sequence (IGNVGA). Amino acids 1 to 13 (MASEPNLRYPTEE) and amino acids 85 to 99 (HNFTLINYSCDLTGV) of the herpesvirus saimiri sequence are not depicted.

report in which a viral mRNA has been shown to have an open reading frame that codes for a collagenlike sequence.

To explain the lack of homology between strains 11 and 484-77 in the right-end $1.8-\mathrm{kbp}$ L-DNA region, we favor the hypothesis that different cellular sequences have been acquired by these strains. There is evidence that herpesvirus saimiri readily integrates cellular sequences into its genome. The virally coded thymidylate synthase (2), dihydrofolate reductase $(50)$, and U-type small $\operatorname{RNAs}(27,51)$ are highly homologous to corresponding human sequences and were probably acquired from the cellular genome. The difference in $\mathrm{G}+\mathrm{C}$ content suggests that the collagenlike sequence may also be of cellular origin $(52 \% \mathrm{G}+\mathrm{C}$, in contrast to $36 \% \mathrm{G}+\mathrm{C}$ in the surrounding viral L-DNA sequences). However, we assume that these cellular sequences then further evolved, since no homology between cellular and viral sequences can be detected by Southern hybridization (32; P. Medveczky, unpublished data). The right-end region of L-DNA of strain 11 (group A) has one open reading frame with no homology to ORF1 or ORF2 of 484-77, as shown, but deletion of the open reading frame results in loss of oncogenicity (35). These results suggest that the two viruses probably transform $\mathrm{T}$ cells by different molecular mechanisms.

The viral message in the tumor-derived cell line is $1.2 \mathrm{~kb}$

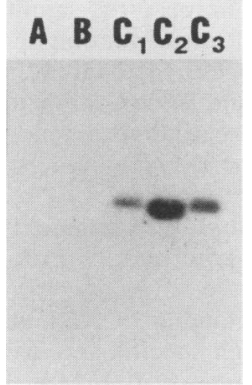

FIG. 7. Southern hybridization to detect collagenlike sequences in different strains representing the three homology groups. Herpesvirus saimiri virion DNA (about $50 \mathrm{ng}$ ) from the different strains was digested with $P v u$ II. The nick-translated DNA probe represented cloned sequences between nucleotides 1269 and 889 . Lane A, Strain 11 (group A); lane B, strain S295C (group B); lane $C_{1}$, strain 484-77 (group C); lane $C_{2}$, strain 487-77 (group C); lane $C_{3}$, strain 505-77 (group C). long and contains a $3^{\prime}$ poly(A) tail, and our data indicate no splicing, unless sequences outside the studied $6.2-\mathrm{kbp}$ region are involved. The mRNA sequence contains two open reading frames, which is unusual but not unprecedented among eucaryotes.

The structure of the saimiri collagenlike (SCOL) sequence is coherent with basic patterns in collagen structure $(4,53)$. In collagen, a nine-nucleotide element codes for Gly-X-Y amino acid triplets ( $\mathrm{X}$ and $\mathrm{Y}$ are frequently proline and hydroxyproline, respectively) which are repeated several hundred times in individual polypeptides of the triple helical structure $(26,36$; for a review, see reference 6$)$. A characteristic element of collagen evolution is a 54-nucleotide unit. The relics of this evolutionary stage are still present in the exons of a chicken collagen, in which most of the 50 exons contain 54 nucleotides $(6,36)$. In herpesvirus saimiri, the 162-nucleotide sequence appears to be the result of exactly three reiterations of a 54-nucleotide unit. The absence of splicing may indicate a reverse transcription step prior to integration into the viral genome.

The perfect invariable repeats are one of the intriguing features of the saimiri collagenlike sequence, since in collagen the $\mathrm{X}$ and $\mathrm{Y}$ positions are highly variable. The presence of the sequence was detected without fragment variability in all tested group C strains by Southern analysis. This demonstrates the conservation of the sequence within the subgroup, which may indicate the biological significance of the saimiri collagenlike sequence.

No evidence is available on the function of the saimiri collagenlike sequence, and the expression of the polypeptide has yet to be demonstrated. It has been suggested that collagen plays a role in cellular growth regulation, usually by down regulating cell division $(7,28,46)$. On the other hand, very small $\left(15,000\right.$ to $\left.17,000 M_{\mathrm{w}}\right)$ collagenlike polypeptides that have stimulating effects on embryonic tissues (42) and bone marrow stem cell culture (52) have been detected. Mitogenic stimulation and cell transformation after a fibronectin fragment with affinity to collagen is bound $(10,20)$ seem to indicate a collagenlike cell surface receptor, which may act in cell growth regulation. Integrin receptors on cytotoxic $\mathrm{T}$ lymphocytes (nonspecific adhesion receptors, e.g., LFA-1, LFA-3, VLA-1, and VLA-2) $(5,16,17,34,41)$ may also be involved in a collagen-related growth regulation.

The cellular and retroviral oncogenes are derivatives of 
normal cellular counterparts with physiological functions (1, 45). These proto-oncogenes act at different stages of signal transduction in the inter- and intracellular pathways of cell growth regulation $(8,15,54)$. No experimental evidence so far has indicated, however, that sequences related to connective tissue proteins are involved in the process. This report raises the possibility of a growth regulatory function for a virally encoded collagenlike polypeptide.

We thank Larry Hardy, Carel Mulder, Rosemary Vassallo, and Douglas Waud for critical reading of the manuscript. We thank Daniel Mullen for the excellent photographic work.

This work was supported by Public Health Service grants RO1 CA43264, RO1 CA39653, and AI 21129 from the National Institutes of Health and biomedical research support grant SOTRR05712 from the National Institutes of Health to the University of Massachusetts Medical School.

\section{LITERATURE CITED}

1. Adamson, E. D. 1987. Oncogenes in development. Development 99:449-471.

2. Bodemer, W., H. H. Niller, H. Nitsche, B. Scholz, and B. Fleckenstein. 1986. Organization of the thymidylate synthase gene of herpesvirus saimiri. J. Virol. 60:114-123.

3. Bornkamm, G., H. Delius, B. Fleckenstein, F.-J. Werner, and C. Mulder. 1976. Structure of Herpesvirus saimiri genomes: arrangement of heavy and light sequences in the M-genome. J. Virol. 19:154-161.

4. Bornstein, P. 1980. Structurally distinct collagen types. Annu. Rev. Biochem. 49:957-1003.

5. Buck, C. A., and A. F. Horwitz. 1987. Cell surface receptors for extracellular matrix molecules. Annu. Rev. Cell Biol. 3:179205.

6. Burgeson, R. E. 1988. New collagens, new concepts. Annu. Rev. Cell Biol. 4:551-577.

7. Buttle, B. J., and H. P. Ehrlich. 1983. Comparative studies of collagen lattice contraction utilizing a normal and a transformed cell line. J. Cell. Physiol. 116:159-166.

8. Chiarugi, V., M. Ruggiero, and F. Porciatti. 1987. Oncogenes and transmembrane cell signalling. Cancer Invest. 5:215-229.

9. Daniel, M. D., L. V. Melendez, R. D. Hunt, N. W. King, M. Anver, C. E. O. Fraser, H. H. Barahona, and R. B. Baggs. 1974. Herpesvirus saimiri. VII. Induction of malignant lymphoma in New Zealand White rabbits. J. Natl. Cancer Inst. 53:1803-1807.

10. DePetro, G., S. Barlati, T. Vartio, and A. Vaheri. 1981. Transformation enhancing activity of gelatin binding fragments of fibronectin. Proc. Natl. Acad. Sci. USA 78:4965-4969.

11. Desrosiers, R. C., A. Bakker, J. Kamine, L. A. Falk, R. D. Hunt, and N. W. King. 1985. A region of the Herpesvirus saimiri genome required for oncogenicity. Science 228:4694-4699.

12. Favoloro, J., R. Treisman, and R. Kamen. 1980. Transcription maps of polyomavirus specific RNA: analysis by two-dimensional nuclease S1 gel mapping. Methods Enzymol. 65:718-749.

13. Fleckenstein, B., and C. Mulder. 1980. Molecular aspects of Herpesvirus saimiri and Herepesvirus ateles, p. 799-812. In G. Klein (ed.), Viral oncology. Raven Press, New York.

14. Gompels, U. A., M. A. Craxton, and R. W. Honess. 1988. Conservation of gene organization in the lymphotropic herpesviruses herpesvirus saimiri and Epstein-Barr virus. J. Virol. 62:757-767.

15. Heldin, C.-H., and B. Westermark. 1984. Growth factors: mechanism of action and relation to oncogenes. Cell 37:9-20.

16. Hemler, M. E., C. Huang, and L. Schwarz. 1987. The VLA protein family. J. Biol. Chem 262:3300-3309.

17. Hemler, M. E., J. G. Jacobson, and J. L. Strominger. 1985. Biochemical characterization of VLA-1 and VLA-2. J. Biol. Chem. 260:15246-15252.

18. Henikoff, S. 1984. Unindirectional digestion with exonuclease III creates targeted breakpoints for DNA sequencing. Gene 28:351-359.

19. Hoheisel, J., and F. M. Pohl. 1986. Simplified preparation of unidirectional deletion clones. Nucleic Acids Res. 14:3605.
20. Humphries, M. J., and S. R. Ayad. 1983. Stimulation of DNA synthesis by cathepsin D digests of fibronectin. Nature (London) 305:811-813.

21. Johnson, D. R., and M. Jondal. 1981. Herpesvirus-transformed cytotoxic T-cell lines. Nature (London) 291:81-83.

22. Jones, K. A., K. R. Yamamoto, and R. Tjian. 1985. Two distinct transcription factors bind to the HSV thymidine kinase promoter in vitro. Cell 42:559-572.

23. Kaschka-Dierich, C., F. J. Werner, I. Bauer, and B. Fleckenstein. 1982. Structure of nonintegrated, circular Herpesvirus saimiri and Herpesvirus ateles genomes in tumor cell lines and in vitro transformed cells. J. Virol. 44:295-310.

24. Kiyotaki, M., R. C. Desrosiers, and N. L. Letvin. 1986. Herpesvirus saimiri strain 11 immortalizes a restricted marmoset $\mathrm{T} 8$ lymphocyte subpopulation in vitro. J. Exp. Med. 164:926-931.

25. Koomey, J. M., C. Mulder, R. L. Burghoff, B. Fleckenstein, and R. C. Desrosiers. 1984. Deletion of DNA sequences in nononcogenic variant of Herpesvirus saimiri. J. Virol. 50:662-665.

26. Kramer, J. M., G. N. Cox, and D. Hirsch. 1982. Comparison of the complete sequences of two collagen genes from Caenorhabditis elegans. Cell 30:599-606.

27. Lee, S. I., S. C. S. Murthy, J. L. Trimble, R. C. Desrosiers, and J. A. Steitz. 1988. Four novel U RNAs are encoded by a herpesvirus. Cell 54:599-607.

28. Liotta, L. A., D. Vembu, H. K. Kleinman, G. R. Martin, and C. Boone. 1978. Collagen required for proliferation of cultured connective tissue cells, but not their transformed counterparts. Nature (London) 272:622-624.

29. McKnight, S. L., and R. Kingsbury. 1982. Transcriptional control signals of a eukaryotic protein coding gene. Science 217:316-324.

30. Medveczky, M. M., E. Szomolanyi, R. Hesselton, D. DeGrand, P. Geck, and P. G. Medveczky. 1989. Herpesvirus saimiri strains from three DNA subgroups have different oncogenic potentials in New Zealand White rabbits. J. Virol. 63:3601-3611.

31. Medveczky, P., C.-W. Chang, C. Oste, and C. Mulder. 1987. Rapid vacuum driven transfer of DNA and RNA from gels to solid supports. Biotechniques 5:242-246.

32. Medveczky, P., E. Szomolanyi, R. C. Desrosiers, and C. Mulder. 1984. Classification of herpesvirus saimiri into three groups based on extreme variation in a DNA region required for oncogenicity. J. Virol. 52:938-944.

33. Melton, D. E., P. A. Krieg, M. R. Rebagliati, T. Maniatis, K. Zinn, and M. R. Green. 1984. Efficient in vitro synthesis of biologically active RNA and RNA hybridization probes from plasmids containing a bacteriophage SP6 promoter. Nucleic Acids Res. 12:7035-7056.

34. Mentzer, S. J., S. H. Gromkowsky, A. M. Kremsky, S. J. Burakoff, and E. Martz. 1985. LFA-1 membrane molecule in the regulation of homotypic adhesions of human B lymphocytes. J. Immunol. 135:9-11.

35. Murthy, S. C. S., J. J. Trimble, and R. C. Desrosiers. 1989. Deletion mutants of herpesvirus saimiri define an open reading frame necessary for transformation. J. Virol. 63:3307-3314.

36. Ohkubo, H., G. Vogeli, M. Mudryj, V. E. Avvedimento, M. Sullivan, I. Pastan, and B. de Crombrugghe. 1980. Isolation and characterization of overlapping genomic clones covering the chicken alpha 2 (type I) collagen gene. Proc. Natl. Acad. Sci. USA 77:7059-7063.

37. Pearson, W. R., and D. J. Lipman. 1988. Improved tools for biological sequence comparison. Proc. Natl. Acad. Sci. USA 85:2444-2448.

38. Rigby, P., M. Dieckmann, C. Rhodes, and P. Berg. 1977. Labeling DNA to high specific activity in vitro by nick translation with DNA polymerase I. J. Mol. Biol. 113:237-252.

39. Roizman, B. 1982. The family Herpesviridae: general description, taxonomy, classification, p. 1-23. In B. Roizman (ed.), The herpesviruses, vol. 1. Plenum Publishing Corp., New York.

40. Roizman, B., L. E. Carmichael, F. Deinhardt, G. de-The, A. J. Nahmias, W. Plowright, F. Rapp, P. Sheldrick, M. Tadahashi, and K. Wold. 1981. Herpesviridae definition, provisional nomenclature, and taxonomy. Intervirology 10:201-217.

41. Ruoslahti, E. 1988. Fibronectin and its receptors. Annu. Rev. 
Biochem. 57:375-413.

42. Sage, H. 1985. Low molecular weight fibroblast collagen: structure, secretion, and differential expression as a function of fetal and cellular age. Biochemistry. 24:7430-7440.

43. Sanger, F., S. Nicklen, and A. R. Coulson. 1977. DNA sequencing with chain-terminating inhibitors. Proc. Natl. Acad. Sci. USA 74:5463-5467.

44. Schirm, S., I. Müller, R. C. Desrosiers, and B. Fleckenstein. 1984. Herpesvirus saimiri DNA in a lymphoid cell line established by in vitro transformation. J. Virol. 49:938-946.

45. Sibbitt, W. L., Jr. 1988. Oncogenes, normal cell growth, and connective tissue disease. Annu. Rev. Med. 39:123-133.

46. Smith, B. D., A. P. Mahoney, and R. S. Feldman. 1983. Inverse correlation of collagen production to anchorage independence and tumorigenicity in $\mathrm{W}-8$ and $\mathrm{M}$ cell lines. Cancer Res. 43:4275-4282.

47. Sugden, B., K. Marsh, and J. Yates. 1985. A vector that replicates as a plasmid and can be efficiently selected in Blymphoblasts transformed by Epstein-Barr virus. Mol. Cell Biol. 5:410-413.

48 Tabor, S., and C. C. Richardson. 1987. DNA sequence analysis with a modified bacteriophage T7 DNA polymerase. Proc. Natl. Acad. Sci. USA 84:4767-4771.
49. Thomas, P. S. 1980. Hybridization of denatured RNA and small DNA fragments transferred to nitrocellulose. Proc. Natl. Acad. Sci. USA 77:5201-5205.

50. Trimble, J. J., S. C. S. Murthy, A. Bakker, R. Grassmann, and R. C. Desrosiers. 1988. A gene for dehydrofolate reductase in herpesvirus. Science 239:1145-1147.

51. Wassarman, D. A., S. I. Lee, and J. A. Steitz. 1989. Nucleotide sequence of HSUR 5 RNA from herpesvirus saimiri. Nucleic Acids Res. 17:1258.

52. Waterhouse, E. J., P. J. Quisenberry, and G. Balian. 1986. Collagen synthesis by murine bone marrow cell culture. J. Cell. Physiol. 127:397-402.

53. Yamada, Y., V. E. Avvedimento, M. Mudryj, H. Ohkubo, G. Vogeli, M. Irani, I. Pastan, and B. de Crombrugghe. 1980. The collagen gene: evidence for its evolutionary assembly by amplification of a DNA segment containing an exon of $54 \mathrm{bp}$. Cell 22:887-892.

54. Yarden, Y. 1988. Growth factor receptor tyrosine kinases. Annu. Rev. Biochem. 57:443-478.

55. Zinn, K., D. DiMaio, and T. Maniatis. 1983. Identification of two distinct regulatory regions adjacent to the human beta interferon gene. Cell 34:865-879. 